\title{
@Q $\odot \Theta \Theta$ Educar, elaborar o passado, desnazificar: Memória histórica e neonazifascismo no início do século XXI
}

Robson Loureiro *

Resumo: Apesar de o nazismo e o fascismo terem sido aparentemente “enterrados” após a $2^{\mathrm{a}}$ Guerra Mundial, atualmente o avanço do nazifascismo causa preocupação em nível mundial. Este artigo trata do conceito de elaboração do passado - negação determinada do objeto - e busca responder como, quando, por que, quanto tempo durou e as principais características do Programa de Desnazificação (PDA) na Alemanha do pós-guerra. Foi uma política pública bemsucedida? Como se deu a participação da educação formal, nesse PDA? As respostas decorrem da análise mediada por uma hermenêutica histórico-filosófica fundamentada na teoria e em aspectos da filosofia da educação de T. Adorno, que visa apreender as razões pelas quais o nazifascismo sempre foi uma ideologia política presente, desde o Zeitgeist que o inaugurou, no início do século XX, até os dias atuais.

Palavras-chave: Elaboração do passado. Negação determinada. Memória histórica. Desnazificação. Neonazifascismo.

\footnotetext{
* Doutor em Educação pela Universidade Federal de Santa Catarina (UFSC). Professor Associado da Universidade Federal do Espírito Santo (UFES). E-mail: robsonloureiro.ufes@uol.com.br ORCID: https://orcid.org/0000-0002-8272-5368 . Apoio: CAPES/UFES
} 


\title{
Educate, Working Through the Past, Denazificate: Historical memoy and neonazifascism in the begin of 21 st century
}

\begin{abstract}
Although Nazifascism was apparently "buried” after World War II, its advance is currently causing worldwide concern. This article deals with the concept of working through the past - a specific negation of the object - and it aims to answer how, when, why, how long it lasted and the main features of the postwar German Denazification Program (DP); was it a successful public policy? How did formal education participate in this DP? The answers derive from the analysis mediated by a historical-philosophical hermeneutics based on the theory and aspects of T. Adorno's philosophy of education, which aims to apprehend the reasons why Nazifascism was ever a present ideology, since the Zeitgeist in which it was opened - at the beginning of the 20th century -, to the present day.
\end{abstract}

Keywords: Elaboration of the past. Specific denial. Historical memory. Desnazification. Neonazifascism.

\section{Éduquer, Travailler à travers le passé "dénazifier": Mémoire historique et néonazifascime au début du 21e siècle}

Résumé: Bien qu'apparemment "enterré" après la Seconde Guerre mondiale, l'avancée du nazifascisme suscite des inquiétudes au niveau mondial. Cet article traite du concept d'élaboration du passé - une négation spécifique de l'objet - et cherche à expliquer comment, quand, pourquoi, combien de temps il dura et les principales caractéristiques du Programme de Dénazification (PDA) de l'Allemagne d'après-guerre. Était-ce une politique publique réussie? Comment 
l'éducation formelle a-t-elle participé à ce PDA? Les réponses proviennent de l'analyse médiée par une herméneutique historico-philosophique basée sur la théorie et les aspects de la philosophie de l'éducation de T. Adorno, qui vise à appréhender les raisons pour les quelles le nazifascisme a toujours été une idéologie actuelle, depuis que le Zeitgeist l'a inauguré, au début du XXe siècle, jusqu’à nos jours.

Mots-clés: Elaboration du passé. Déni spécifique. Mémoire historique. Dénazification. Néonazifascisme.

\section{Introdução}

O dom de despertar no passado as centelhas da esperança é privilégio exclusivo do historiador convencido de que também os mortos não estarão em segurança se o inimigo vencer. Esse inimigo não tem cessado de vencer (BENJAMIN 1994, p. 224-225).

O objeto de investigação deste artigo é o conceito de elaboração do passado (Aufarbeitung der Vergangenheit), entendido como negação determinada do objeto (ADORNO, 1995a), cuja análise é mediada por uma hermenêutica histórico-filosófica de orientação teórico-metodológica fundamentada na teoria crítica da sociedade. Para tanto, problematizo o Programa de Desnazificação da Alemanha (PDA) - política pública 
proposta pelos Aliados, no imediato pós $2^{\mathrm{a}}$ Guerra Mundial: em que de fato consistiu, quando foi oficialmente instaurado e quanto tempo vigorou o PDA; quais são suas principais características; até que ponto é possível afirmar que fora bem-sucedido e qual o papel da educação formal nesse programa. O escopo é compreender as razões pelas quais o nazifascismo sempre esteve presente, desde o Zeitgeist que inagurou seu surgimento, no início do século $\mathrm{XX}$, até os dias atuais. A hipótese que orienta a pesquisa fundamenta-se na observação de Hertz (1948), segundo a qual o PDA foi um fiasco. A partir dessa constatação, sustenta-se que, além de um fiasco, o PDA foi um fracasso, no entanto, isso significou o seu sucesso. Eis, portanto, uma possível chave de leitura para se compreender tanto a continuidade como o fortalecimento da ideologia neonazifascista, que nesse início do século XXI ronda a Alemanha e inúmeros outros contextos geopolíticos.

A esperança, à qual Walter Benjamin faz referência na epígrafe acima, tem a ver com a ideia de transformação social que visa a cessar a vitória do inimigo. Este, que hoje pode ser identificado como a racionalidade ultraneoliberal que domina todos os âmbitos do mundo da vida (DARDOT; LAVAL, 2016). É também a uma hipótese que alimenta o desejo de um conjunto considerável de pessoas que historicamente tem lutado, desde a segunda metade do século XIX, e início do XX, contra a hegemonia do sistema/modo de produção capitalista. Nessa perspectiva, nos últimos anos, em função da crise (2008) do capital, têm sido cada vez mais recorrentes as manifestações de movimentos sociais organizados que lutam em defesa de uma ordem social contrária às políticas ultraneoliberais que arrastam para a miséria bilhões de seres humanos, em especial a classe 
que vive do trabalho, que é a mais vulnerável e vítima da insana volúpia incontida do Estado capitalista, também responsável pela irrefreável destruição da natureza (HARVEY et. al, 2012). Sem contar as inúmeras análises (HARVEY, 2016; CHOMSKY, 2016; BOURDIEU, 1998) que reconhecem os sinais que indicam a fragilidade exponencial, não apenas da forma capitalista de produção social da existência, mas do tipo de regime democrático sustentado pela plutocracia (BANDEIRA, 2018; CHOMSKY, 2016) que o caracteriza enquanto sistema de governo (BITTAR, 2011). No atual Zeitgeist, aquele antigo desejo, ao qual Walter Benjamin faz referência, na epígrafe desse artigo, é renovado e se destaca como um facho de esperança que ilumina aqueles que sustentam a hipótese de uma sociedade não capitalista.

A fase áurea da democracia capitalista só foi possível quando ela se potencializou em nazifascismo (HOBSBAWM, 1995), cuja ideologia não foi derrotada com o fim da $2^{\mathrm{a}}$ Guerra Mundial e, atualmente, representa uma política calcada na liquidação daquela hipótese (transformação social para impedir que o inimigo pare de vencer). Em nível global, a partir das décadas de 1980 e 1990, é possível perceber a prevalência de uma profunda crise e concomitante reestruturação da organização do capital. Após o abalo sistêmico de 2008, tanto nos Estados Unidos como na Europa, fortaleceu-se ainda mais a teoria neoliberal, cujas teses têm início no final da década de 1930 (HAYEK, 1958), mas só começaram a ser aplicadas depois do colapso do sistema monetário internacional, na turbulenta década de 1970 (STREECK, 2018), com o endurecimento das políticas neoconservadoras contra as lutas da classe trabalhadora nos governos Reagan (EUA), Thatcher (Inglaterra), Kohl 
(Alemanha), Pinochet (Chile) e Deng, na China (HARVEY, 2016, p. 10). Por isso, é sintomático que, após 2008, a Europa tenha passado a viver um boom de revigoramento das forças políticas de extrema direita. Fenômeno que transcende aquele continente, o neonazifascismo resgata e expõe, sem nenhum pudor, seus antigos ideais patrióticos cujas consequências revelam o recrudescer do grito de sofrimento das vítimas que não param de aumentar. Isso implica considerar que o problema do nazifascismo rompeu o tempo e o espaço originário onde tomou corpus (Alemanha e Itália) e, como expressão áurea do capital, ele acompanha de perto sua mundialização na forma ultraneoliberal, que desautoriza a mão esquerda (BOURDIEU, 2008) do plutocrático Estado capitalista na implementação da política econômica que foi responsável pela proteção social - Welfare State - de um contingente significativo da classe trabalhadora (STREECK, 2018).

Em síntese, desde as primeiras organizações, na década de 1920, tanto o fascismo, na Itália, quanto o nazismo, na Alemanha, têm sido expressões políticas de extrema direita que sempre expuseram a contradição inerente à ordem social capitalista. Ainda que aparentemente “enterrados", em razão da derrota da Alemanha e da Itália, na $2^{\mathrm{a}}$ Guerra Mundial, no cenário político contemporâneo, o neonazifascismo confirma sua força ideológica, causa preocupação e nos faz pensar quando será acionado o freio de contenção dessa locomotiva desvairada.

$\mathrm{Na}$ primeira parte do artigo, para entender o PDA, apresento um panorama sobre a política pública para a educação no Estado nazista. No segundo item, destaco algumas características do PDA, particularmente aqueles vinculados à educação e à cultura. Em seguida, exponho 
evidências relativas ao avanço da extrema direita, em nível mundial, bem como apresento as possíveis motivações que ajudam a explicar esse fenômeno, cujas razões têm a ver tanto com a ordem e a organização do capital (determinação objetiva), quanto com as condições subjetivas. No âmbito daquela, jaz a orientação da política econômica que a sustenta. Com relação às determinações subjetivas, defendo que em função do fracasso do PDA, a esfera pública alemã não realizou a elaboração do passado - negação determinada do objeto de amor (o Führer/nazismo) - o que tem contribuído para a reprodução do sofrimento, cuja origem tem a ver com as feridas expostas pelo trauma coletivo.

\section{Aspectos da educação no Estado nazista}

Quais são os princípios que sustentaram a práxis política do nazifascismo alemão, como foram divulgados na esfera pública e incorporados pelos alemães, no período do Estado nazista (1933-1945)? A ideologia nazifascista foi amplamente divulgada, desde o início de sua fundação, por uma rede articulada de canais próprios da indústria cultural da época - editoras, jornais, rádio, cinema etc. -, dentre eles, o jornal Völkischer Beobachter - "Observador da Raça" (DENNIS, 2014) -, comprado pelo Partido Nazista (PN) no mesmo ano de sua fundação (1920) tendo sido, até 1933, o principal meio de divulgação dos seus ideais. Fundado na Alemanha, com a mesma marca ideológica do fascismo italiano (HOBSBAWM, 1995), até 1930 o PN era antiliberal e 
anticapitalista. Entretanto, com pouco tempo de existência, passou a apoiar e ser patrocinado por industriais de dentro e fora da Alemanha, quase todos adeptos dos ideais nazistas. Não obstante sua nomenclatura supostamente aludir à ideia de que se trata de um partido socialista dos trabalhadores, seus princípios podem ser resumidos em uma mixórdia de concepções saturadas por uma cosmovisão ultranacionalista - defesa do sangue e da pátria; da tradição - mito da raça pura, que orientou (e orienta) milícias paramilitares racistas - antissemitas -, oriundas das forças populares anticomunistas do pós $1^{\text {a }}$ Guerra etc. (EVANS, 2008; HOBSBAWM, 1995). Tanto na Alemanha como na Itália, além dos capitalistas, os nazifascistas receberam apoio de frações da classe trabalhadora, operários urbanos e trabalhadores rurais desiludidos com a República de Weimar (1919-1933), bem como da pequena burguesia que havia sofrido com a erosão de seu status social, tanto no pós-guerra (1918), como na grande recessão do capital, em 1929. Boa parte desse "bloco inorgânico" passou a aderir às teses nazistas, em especial à ideia segundo a qual a culpa do fracasso alemão, na $1^{\text {a }}$ Guerra Mundial, fora dos comunistas e judeus (STANLEY, 2019; EVANS, 2008; HOBSBAWM, 1995).

Ao longo de todo o período, que vai de 1933 a 1945, a política educacional nazista objetivou formar os alemães para serem obedientes servidores do Estado, ao invés de pessoas autônomas capazes de autorreflexão crítica. Nas escolas, os estudantes, particularmente os meninos, passavam cinco horas por dia em aulas de educação física/esportes e em apenas duas horas por dia tinham aulas em outras disciplinas. O currículo escolar forçou alunos e professores a seguirem os princípios morais da ideologia nazista, tais como militarismo, xenofobia, 
masculinidade agressiva, ultranacionalismo, mito da superioridade racial (sangue e pátria/solo) dos alemães arianos, e os temas escolares superdimensionavam esses valores a partir de materiais didáticos (FOX, 2017; EVANS, 2012; SHIRER, 2008).

A nazificação dos jovens teve início em 1922, por meio da Juventude Hitlerista (JH), uma seção específica do PN que recrutava os não aptos a servirem nas Tropas de Assalto - milícias do partido. As meninas recebiam lições próprias da formação militar e, por volta dos 14 anos de idade, alistavam-se como Jung Mädel (“jovens donzelas”), cujo treinamento imitava o dos rapazes da mesma idade: longas marchas nos fins de semana, com pesadas mochilas e a usual catequese da ideologia nazista. A doutrinação enfatizava que o papel da mulher devia ser totalmente voltado para os fins da procriação calcada em uma maternidade sadia com vistas à reprodução de uma prole saudável. Aos quatorze anos de idade, as meninas aderiam à Liga das Moças Alemãs - Bund Deutscher Mädel-, e lá permaneciam até completarem vinte e um anos. Com a idade de dezoito, prestavam um ano de serviço nas fazendas — as Land Jahr, equivalente à Cooperação pelo Trabalho dos rapazes -, cuja tarefa consistia tanto em trabalhos domésticos como na lida com a labuta no campo (SHIRER, 2008).

A partir de 1936, a JH recebeu o status de instituição educativa oficial e autônoma e respondia somente ao Führer; em 1939, a filiação tornou-se obrigatória e a JH contava com quase nove milhões de filiados. Os pais que não inscrevessem seus filhos podiam ser multados ou presos, caso os impedissem de se filiarem (EVANS, 2012; SHIRER, 2008). 
Em seu livro, Mein Kampf, Adolf Hitler esboça ideias sobre a natureza e o propósito da educação no Estado racial que pretendia construir na Alemanha: antes da atividade intelectual, dever-se-ia treinar corpos saudáveis: "O treinamento de capacidades mentais é apenas secundário" (HITLER citado por EVANS, 2012, p. 360).

Desde 1938, a política educacional abrangeu todas as séries e uma variedade de diferentes matérias. O ensino da língua alemã enfocava os padrões de fala como um produto do ambiente racial; as palavras eram concebidas como instrumentos da consciência nacional alemã; os tipos de fala, como expressões do caráter (EVANS, 2012). Os livros didáticos de aritmética básica, compilados sob a orientação do Ministério da Educação, abordavam a "aritmética social", que envolvia cálculos elaborados para efetuar um doutrinamento subliminar em áreas-chave. Às crianças era solicitado que calculassem "quanto custaria ao Estado para manter um doente mental vivo em um asilo". Exercícios cujos enunciados apontavam para uma aversão à capacidade crítico-argumentativa, como por exemplo: "Estima-se que a proporção de sangue nórdico no povo alemão seja de 4/5 da população" ou, "Um terço dessa população pode ser considerada loira. De acordo com essas estimativas, quantas pessoas loiras deve haver na população alemã de 66 milhões?”. Havia também exercícios escolares que valorizavam ideias expansionistas, como, por exemplo, calcular a porcentagem de falantes de alemão na Renânia, enquanto os de latim sugeriam que os alunos traduzissem frases que enfatizassem a glória militar e o valor do sacrifício pessoal (EVANS, 2012, p. 352).

A base moral da ideologia nazifascista fundamenta-se na potencialização da agressividade, moldada pela brutalidade de uma 
disciplina calcada na obediência mediada pela força como princípio básico do respeito absoluto à hierarquia verticalizada. Quase toda uma geração de jovens alemães, entre os dez e dezoitos anos de idade, no período de 1933 a 1945, apropriou-se dessas supostas "virtudes", fundamentadas na educação pela disciplina por meio da dureza, reproduzidas mediante uma ininterrupta doutrinação fortalecida pela propaganda e publicidade cuja mensagem concebia que o poder pertencia aos mais fortes; que os vencedores tudo levam; e pessoas de raça inferior - judeus, ciganos, eslavos, negros - podiam e deviam ser livremente abatidos, exterminados (EVANS, 2008). Para Hitler (citado por EVANS, 2008, p. 361), o jovem alemão do futuro deveria ser "[...] esbelto e flexível, veloz como cães, rijo como couro e duro como o aço Krupp". Por isso, seu treinamento visava a formar "o novo" ser humano: homens e mulheres disciplinados e saudáveis. A educação, segundo Hitler, começa na juventude e é contínua: nunca termina. Inicia com a criança e acaba no "velho combatente". Para ele, sob o $3^{\circ}$ Reich, ninguém será capaz de dizer que teve um tempo em que foi deixado inteiramente sozinho e por conta própria (HITLER citado por EVANS, 2012, p. 361).

A "reforma" educacional nazista foi apelidada de "nova escola" (BECKERT, 2016; HANNOUN, 1997), cuja filosofia da educação, paradoxalmente, fundamentou-se em autores com perspectivas teóricas díspares, mas também com teses afins, dentre eles Immanuel Kant, JeanJacques Rousseau, Friedrich Hegel, Friedrich Nietzsche, Martin Heidegger, Alfred Rosemberg, Adolf Hitler, Ernst Kriek (HANNOUN, 1997). 
Em síntese, a filosofia da educação nazista pode ser concebida como uma bioestética, baseada nos seguintes preceitos: o corpo (guerreiro) é a exigência estético-bélica primeira da formação - primado do corpo sobre a inteligência, com fins e ênfase na bioafetividade; a educação da vontade - adaptação ao primado absoluto das exigências da vida prática -, ou seja, o ser aí (Dasein) heideggeriano (HANNOUN, 1997) deve ser capaz de tomar uma decisão e dotado de força de vontade; a submissão do indivíduo ao grupo - sacrifício de si próprio -, fundamentada em uma sociobiologia (fusão da raça e da cultura alemã, consideradas superiores a todas outras); autoritarismo - à escola cabe ensinar a obediência e os alunos devem aprender a se calar em face de uma censura justificada e, também em silêncio, suportar a injustiça (HANNOUN, 1997).

\section{O magistério no Estado alemão nazifascista}

No caso dos professores, após 1933, aqueles que desejassem alguma promoção na carreira do magistério, e quisessem continuar no cargo, quer acreditassem ou não no que diziam, tinham que simular serem nazistas exemplares. Não por acaso, quatro meses após a posse do chanceler Adolf Hitler, o Estado nazista criou a Lei do Reich para o Restabelecimento de um Serviço Público Profissional. Para dar suporte à lei, montou-se uma rede de comitês de investigação. Atulhados de nazistas ativos e controlados pelos líderes regionais e funcionários nazistas locais, esses comitês exoneraram não apenas professores, servidores públicos enquadrados nas cláusulas da lei, mas também diretores de escolas. Em 
torno de $32 \%$ das mulheres diretoras de escolas secundárias na Prússia foram despedidas (EVANS, 2012, p. 354).

Em sala de aula, os professores tinham que se autopoliciar para não proferirem palavras que supostamente expressassem algum tipo de pensamento incauto capaz de ferir a "moral" nazista. Qualquer comentário com esse teor era censurado pelos pares ou mesmo pelos alunos que denunciavam os professores considerados suspeitos. Como observa Evans (2012), é bem provável que o medo de ser alvo de uma denúncia fosse uma realidade no dia a dia do extenuante trabalho docente. Era comum que escolas e professores sob suspeita recebessem visitas frequentes de inspetores; aqueles que tentassem reduzir o impacto do ensinamento, cada vez mais nazificado, que eram obrigados a ministrar, deviam considerar cada palavra antes de falar, visto que os filhos dos velhos 'companheiros de Partido' os vigiavam constantemente, com o escopo de denunciá-los (EVANS, 2012, p. 356).

Da educação básica às universidades, tudo foi rapidamente nazificado: os manuais foram reelaborados, os currículos modificados e o livro Minha luta fora convertido (nas palavras do Der Deutsche Erzieher, órgão oficial dos educadores) em “[...] nossa infalível estrela polar pedagógica" (SHIRER, 2008). Quem não visse a "nova luz" era demitido. Para fortalecer a convicção ideológica, os professores eram obrigados a realizar treinamento intensivo para a assimilação dos princípios nazifascistas, com destaque às doutrinas raciais. Todos, desde a educação infantil até a universidade, deviam se associar à Liga dos Professores Nazistas, legalmente responsável pela coordenação ideológica e política da categoria. A partir de 1937, com a Lei do Funcionalismo Civil, foi cobrada 
a execução da vontade do Partido e a qualquer momento o professor devia estar pronto para defender o Estado nazista. Como servidores civis, estavam sujeitos às leis raciais que proibiam os judeus de atuarem no magistério. Para tanto, prestavam juramento que seriam leais e obedientes a Adolf Hitler. Só aqueles que serviam em alguma seção militar, na Cooperação de Trabalho ou na Juventude Hitlerista, podiam seguir a carreira do magistério.

Com relação à educação acadêmica, os nazistas a consideravam inútil. O mais importante era ocupar o cérebro jovem com matérias que tivessem um fim utilitário. Os temas acadêmicos deveriam ser ensinados apenas por meio de "[...] um resumo do material, voltados especificamente para os interesses da raça" (EVANS, 2012, p. 356). De acordo com Shirer (2008), apesar de as cifras oficiais contabilizarem em torno de 2.800 professores e instrutores demitidos durante os primeiros cinco anos do regime nazista, uma grande maioria deles permaneceu em seus postos. No início do outono de 1933, por volta de 960 docentes, liderados por sumidades, dentre eles o filósofo Martin Heidegger, que assumiu a Reitoria da Universidade de Freiburg, manifestaram publicamente apoio a Hitler e ao regime nazista. Os candidatos à docência universitária deviam aguardar seis semanas em um campo de observação. Após esse período, técnicos nazistas avaliavam se as opiniões e o caráter dos professores eram compatíveis com a ideologia nazi e depois apresentados ao Ministério da Educação, que emitia as licenças e os liberavam, ou não, com base na confiança política dos candidatos, para atuarem no magistério de nível superior. 
Após duas décadas de bombardeio ideológico nazifascista, que ocupou todos os âmbitos da esfera pública responsável pela formação de toda uma juventude que participou da catástrofe, seria possível desnazificar a Alemanha?

\section{O Programa de Desnazificação (PDA) na Alemanha: reeducar para a democracia?}

No mesmo século, em um intervalo de pouco mais de duas décadas (1914/1939), a Alemanha foi responsável pelo início de dois grandes conflitos bélicos mundiais. Saiu derrotada da $1^{a}$ Guerra (19141918); viveu tanto o esplendor cultural como o caos social da República de Weimar (1918-1933), que foi palco do surgimento do nazismo e, logo em seguida (1939), declarou o início da $2^{\text {a }}$ Guerra Mundial. Esta deixou um legado de caos, escombros materiais e danificação moral. A sociedade alemã ficara sob ruínas. Não havia mais governo, sistema de ensino, forças armadas. Quase tudo havia sido destruído. O bombardeio ocasionado pelos Aliados, particularmente Inglaterra e Estados Unidos (EUA), deixou cerca de 26 milhões de alemães desabrigados. Mais de 75 milhões de mortos: eis o legado da $2^{\text {a }}$ Guerra (EVANS, 2008). No "Breve Século XX" (19141991), Eric Hobsbawm (1995) estima que teriam morrido cerca de 187

milhões de pessoas, vítimas da $2^{\mathrm{a}}$ Guerra e outros eventos. O número é contestado por Leitemberg (2006), para quem as mortes teriam chegado a 231 milhões de pessoas. Só na $2^{\mathrm{a}}$ Guerra Mundial, morreram 45 milhões 
de civis. Na Alemanha, doze anos de nazismo foram suficientes para produzir a carnificina de 40 milhões de combatentes alemães, metade civis, dentre eles, mais de 5.7 milhões morreram em defesa da ideologia nazifascista, em prol da "pureza racial” (HEILIG; BÜTTNER; LUTZ, 1991).

Naquele contexto de ruínas, $60 \%$ das escolas estavam destruídas; a maior parte dos professores havia morrido na guerra, ou estava presa ou com sequelas adquiridas em combate que a impossibilitava exercer qualquer tipo de trabalho (RÖHRS, 1977). Contudo, a tarefa mais difícil dos Aliados não era apenas reconstruir o país derrotado, mas dizimar o nazismo que ocasionou a catástrofe. Portanto, a desnazificação pode ser entendida como um processo jurídico-judicial e educacional/cultural realizado entre 1945 e 1948, cujo objetivo foi levar a julgamento os líderes do $3^{\circ}$ Reich e purgar todos os elementos do nazismo da vida pública alemã (FOX, 2017). Contraditoriamente, a desnazificação foi pela primeira vez sugerida em uma reunião realizada no Pentágono (EUA), no ano de 1943, com o escopo de propor programas de reforma no sistema judiciário alemão (DACK, 2016). Dois anos depois, na Conferência de Potsdam, os EUA, a Inglaterra e a União das Repúblicas Socialistas Soviéticas (URSS) confirmaram o acordo (Yalta, maio de 1945), no qual defenderam a necessidade de se realizar aquilo que depois ficou conhecido como os "quatro dês": desnazificação, desmilitarização, descartelização (quebra de grandes conglomerados industriais alemães) e democratização (FOX, 2017; DACK, 2016; BARK; GRESS, 1989; EVANS, 1989). A versão germanizada da Lei para a Libertação do Nazismo e do Militarismo foi aprovada em 5 de março de 1946 e a cerimônia de assinatura foi 
simbolicamente realizada em Munique, berço do nazismo e cidade favorita de Hitler.

No pós-guerra, a Alemanha foi dividida entre as principais forças aliadas (EUA, Inglaterra e Rússia): de um lado, a República Federativa Alemã (RFA), sob domínio do "bloco" capitalista; de outro, a República Democrática Alemã (RDA) - Alemanha Oriental, administrada pela antiga URSS. Do lado Ocidental, os EUA tornaram o PDA a principal agenda política da intervenção e foram responsáveis pela primeira fase (maio de 1945 - março de 1946) do programa (COATES, 2014). Foi então montada uma rede de desnazificação, que contou com 545 tribunais e a participação de cerca de 22.000 funcionários alemães (que não foram analisados, tampouco desnazificados), sob o comando da Divisão Especial do Exército dos EUA (TAYLOR, 2011, p. 281). Todos os alemães adultos deveriam ser convocados a comparecer nos tribunais, onde a conduta deles durante o $3^{\circ}$ Reich era examinada e inserida em cinco categorias: infratores principais, infratores, infratores menores, simpatizantes e não envolvidos. O objetivo era definir com precisão os tipos de comportamento associados a cada categoria e estabelecer a punição apropriada, que variava desde a prisão à pena de morte, para os grandes infratores; o confisco de bens; a proibição de exercer a profissão; cortes nos salários; restrições de viagem ou registro compulsório junto às autoridades (BARK; GRESS, 1989; DACK, 2016; EVANS, 2018). Além desse aspecto judicial, a educação formal e a cultura - em especial o cinema - foram as duas principais áreas que contribuíram com o PDA. Nesse sentido, as forças democráticas, que incluíam pais, professores, a juventude alemã antifascista, todos foram 
convocados para apoiar o programa educacional de desnazificação e democratização.

Ao menos no discurso, na RFA, a ideia era eliminar o nazismo de todas as estruturas e instituições públicas da Alemanha, promover uma "reforma profunda" da estrutura escolar, desnazificar a equipe de professores e remover a ideologia nazi do currículo e dos livros didáticos. Esse era o "programa de educação dos jovens" da nova geração, que deveria aprender os valores democráticos para a reconstrução pacífica do país (FOX, 2017; MESETH, 2012, p. 19; DACK, 2016). Contudo, o PDA não se limitava a ações dessa natureza. Com base em "estudos científicos", publicados na década de 1940, a ideia de reeducação teria sido importada da psiquiatria. Na RFA, o protocolo seguiu os pressupostos que fundamentavam a prática adotada no campo psiquiátrico. À época, alguns pesquisadores defendiam que, por causa da megalomania envolta ao culto da raça pura e beligerância, o comportamento dos alemães se assemelhava ao fenômeno da paranoia. De acordo com tal diagnóstico, para serem reabilitados, os nazis deveriam se submeter a psicoterapias alinhadas à medicina da época. A ideia implícita considerava que se submetessem ao processo aceitariam o governo do Estado democrático. Com esse procedimento, e por meio de uma filosofia pragmática, os alemães se reorientariam. Em outros termos, "curar" os alemães do mal significava isolá-los de qualquer influência do passado (PRONAY, 1985; CULBERT, 1985).

O mais intrigante é que todo o suposto desejo de se eliminar o nazifascismo da sociedade alemã parece ter caído por terra quando, em maio de 1948, a Zona de Ocupação Militar governada pelos EUA passou a 
responsabilidade do programa para os próprios alemães. Esse evento foi o estopim para controvérsias, e muitos autores (EVANS, 2018; FOX, 2017; DACK, 2016; BARK; GRESS, 1989; GRIFFITH, 1950) consideram que o PDA, mais que um fiasco (HERTZ, 1948), foi um fracasso. Mas, qual a motivação dessa tese? Primeiro: o PDA não conseguiu impedir que 6,5 milhões de filiados do partido nazista perdessem cargos de responsabilidade. No pós-guerra, houve grande necessidade de pessoal formado: juízes, médicos, advogados, cientistas, engenheiros etc. Inúmeros carrascos nazis, que haviam condenado dissidentes políticos nas cortes do $3^{\circ}$ Reich, participado das mortes nos programas de "eutanásia" nos hospitais, pregado a doutrina nazista nas escolas e nas universidades ou participado de "assassinatos oficiais" no serviço civil retomaram seus empregos (EVANS, 2008, p. 414).

Em face desse argumento, lanço duas hipóteses. A primeira argumenta que por ter sido um fracasso, o PDA teria sido bem-sucedido. Isso porque, nem os Aliados Ocidentais, tampouco os próprios alemães tinham qualquer real intenção de desnazificar a Alemanha. Há muitas razões para que isso seja mais do que uma hipótese: 1) a rigor, desnazificar toda a Alemanha não era tarefa simples em um país atolado no caos (ruína moral, espiritual, material) generalizado; 2) antes de a Guerra atingir, de forma direta, a Inglaterra e os EUA, todos os crimes nazistas, incluídos aí o assassinato de dissidentes políticos e os campos de extermínio, pareciam de fato irrelevantes; 3) o nazifascismo, nas suas versões alemãs e italianas, compartilhou com os Aliados Ocidentais um inimigo afim: o comunismo 
ou qualquer tipo de ideal socialista derivado do tradicional movimento da classe trabalhadora (EVANS, 2018; HOBSBAWM, 1995).

Sobre esse terceiro item, basta recorrer ao fato de que dez anos antes do início da $2^{\mathrm{a}}$ Guerra, os capitalistas, com apoio de parcela das forças armadas da "mais democrática" nação do mundo - EUA -, não apenas apoiaram Hitler e Mussolini, como tentaram dar um golpe de Estado para derrubar o presidente Franklin Delano Roosevelt; acabar com as políticas do New Deal e implantar uma ditadura fascista inspirada nos modelos italiano e naquilo que se avizinhava na Alemanha (BANDEIRA, 2018, p. 38). Contudo, mesmo fracassado o golpe de Estado, a simpatia pelo nazifascismo continuou: "Em Wall Street, desde o início da década de 1930, o comunismo era temido, mas o fascismo, admirado como avantgarde. Por longo tempo, diversos banqueiros [...] negociaram com o regime nazista e lhe concederam financiamento de cerca de US\$7 bilhões, naquela década" (BANDEIRA, 2018, p. 42). Mas, ainda que o "núcleo central" do governo estadunidense supostamente não fosse nazifascista, é no mínimo espantoso o fato de que capitalistas como Henry Ford, Prescot Bush (avô do ex-presidente George W. Bush), foram não apenas admiradores, mas financiadores do nazifascismo na Alemanha e Itália. No caso de Bush, ele teria sido tanto financiador como fornecedor de armas para o Estado nazista; Henry Ford começou a financiar o Partido Nazista em 1920 e, até 1944, ele pessoalmente enviava entre 10 a 20 mil marcos, todos os anos, como presente de aniversário para Adolf Hitler (BANDEIRA, 2018).

Portanto, em função desse contexto, é razoável pensar que todos os esforços, em matéria de desnazificação, propostos pelos Aliados 
Ocidentais, em especial pelos EUA e Inglaterra, foram pouco convincentes e efetivos. Ademais, após 1946, a quase totalidade dos servidores públicos incorporados ao Estado alemão havia tido, direta ou indiretamente, alguma ligação com o nazismo: entre 1949-1963, período governado pelo Chanceler Konrad Adenauer, 80\% dos juízes e procuradores, servidores da RFA, tinham sido membros atuantes do partido nazista e mais de 8.000 deles ocuparam cargos públicos importantes no governo (EVANS, 2018; FREI, 2012). Em pelo menos duas ocasiões (1951 e 1954), a RFA anistiou criminosos nazistas. Ao todo foram mais de 4 milhões de anistiados: dentre eles, mais de 900 mil filiados diretos ao partido (TØLLEFSEN, 2006).

Para agravar ainda mais a tese sobre o fracasso do PDA, no imediato pós-guerra, milhões de alemães tiveram que preencher e entregar questionários cujo escopo era conhecer suas atividades e crenças durante o $3^{\text {o }}$ Reich. Muitos foram para os tribunais e, como visto, avaliados e classificados em categorias como: infratores principais, infratores, infratores menores, simpatizantes e não envolvidos. Na Zona de Ocupação Militar Ocidental, mais de 3,6 milhões de pessoas participaram: 1.677 foram classificadas como "principais responsáveis", mais de 23 mil foram "incriminadas"; menos de 5\% foram consideradas nazistas convictos; 996 mil (27\%) foram categorizadas apenas como membros nominais do Partido Nazista; 1.214 .000 alemães (33\%) foram isentados de qualquer ligação significativa com o nazismo. Na época (1948), 783 mil alemães não foram acusados; 358 mil foram anistiados e 125 mil permaneceram sem classificação. Em um processo semelhante, executado na Zona Militar Soviética, mais de 300 mil pessoas foram demitidas do emprego e 83 mil 
foram completamente impedidas de assumir outro posto legal de trabalho. Em linhas gerais, o PDA não foi capaz de impedir que 6,5 milhões de filiados ao partido nazista perdessem seus empregos. Isso não apenas pela dificuldade e complexidade da tarefa, com inúmeras resistências em todos os âmbitos, inclusive da população jovem que não se conformava com o fato de a Alemanha ter fracassado em mais uma Guerra e o herói mítico ter se matado (FOX, 2017), mas porque desnazificar deveria continuar como fiasco necessário.

\section{Consequências do fracasso da desnazificação: mundialização do neonazifascismo}

A segunda hipótese que apresento, fundamentada em inúmeros eventos ocorridos nesse início de século XXI, considera que além do fracasso do PDA, deve-se levar em consideração outras determinações para se compreender as razões que nutrem a atual e bem-sucedida expansão das forças neonazifascistas que têm ascendido ao poder ou lutam para ocuparem a direção do Estado. É cada vez maior a lista de países onde cresce a força da extrema direita representada por partidos que defendem uma agenda política fundamentada em ideais ultranacionalistas supremacia branca, antissemitismo etc. Seus membros unem-se em torno de fantasias genocidas contra judeus, negros, hispânicos, gays e qualquer um que se oponha ao poder branco (DAVIES; JACKSON, 2008; MELZER; SERAFIN, 2013). Trata-se de um fenômeno sem precedentes, desde os anos 1930, pois os partidos de extrema direita alcançaram entre 
$10 \%$ e $20 \%$ dos votos durante a última década (LÖWY, 2015). Não obstante, essa ideologia também tem conquistado a maior plutocracia do planeta: a "democracia" estadunidense (CHOMSKY, 2016). A evidência está na eleição (2017) de Donald Trump para presidente, cuja retórica carrega e provoca uma mistura de medo xenófobo contra latinoamericanos, muçulmanos, afrodescendentes; misoginia assentada em misticismo; teorias de conspiração paranoica sobre seus rivais e políticas isolacionistas (STANLEY, 2019; INGLEHART; NORRIS, 2016).

Parte do noticiário internacional (TORRES, 2017; HUNT, 2017; FOSTER; 2016; IGNATZI, 2013; IVARSFLATEN; GUDBRANDSEN, 2012; POGGIOLI, 2012) sugere que no contexto atual o "espectro" do neonazifascismo assombra, não apenas a Europa. Portanto, além da hipótese relativa ao fracasso da desnazificação, cujo Programa emblemático deu-se na Alemanha do pós-guerra (que certamente não teve algo similar em outros países), quais seriam as motivações para o aumento desse fenômeno - neonazifascismo? Löwy (2015) considera importante não se reduzir a explicação das motivações para o crescimento acelerado do neofascismo, em especial na Europa, a uma abordagem economicista. Ele observa que a crise econômica de 2008 atingiu a quase totalidade dos países europeus, mas alguns deles - Espanha, Portugal, Irlanda, por exemplo - não tiveram uma ascensão da extrema direita. Na Grécia, país muito afetado pela crise, o partido neonazi Aurora Dourada teve um visível crescimento, mas não conseguiu atingir a mesma influência que a coalizão de esquerda, simbolizada pelo Syriza. A análise de Löwy (2015) é pautada em uma materialidade histórica - eventos geopolíticos que merecem ser considerados -, pois o fenômeno é uma síntese de múltiplas, 
combinadas e contraditórias relações e são inúmeras as causas que explicam o recrudescimento das forças políticas de extrema direita: a longínqua tradição antissemita, presente em diversos países europeus; as forças políticas que se uniram em torno da ideologia nazifascista, durante a $2^{\mathrm{a}}$ Guerra; a "agenda geopolítica" colonial (à revelia das políticas anticolonialistas) presente na estrutura de muitos Estados-Nações seriam, de acordo com Löwy (2015), aspectos a serem considerados para se compreender o crescimento da extrema direita na Europa.

Sem deixar de assimilar a sugestão de Löwy (2015), em última instância há, sim, que se considerar a análise hermenêutica fundamentada nas condições materiais de produção da existência, cuja ordenação é garantida pela hegemonia da economia política neo e ultraneoliberal administrada pelo capital financeiro - domador e expropriador do Estado capitalista (DARDOT; LAVAL, 2016; BITTAR, 2011) - por meio de um complexo sistema plutocrático travestido de democracia (BANDEIRA, 2018; CHOMSKY, 2016). De qualquer forma, se no pós-guerra, o início, ainda que "tímido", da ascensão dos partidos neofascistas na Europa remonta à metade da década de 1980, em função de um acelerado processo de desindustrialização, da crise do Estado de bem-estar social seguida de medidas políticas conservadoras, privatizações e reformas do setor público (IVARSFLATEN; GUDBRANDSEN, 2012), o crescimento da ideologia fascista ficou mais visível quando os nefastos efeitos da crise econômica de 2008, nos EUA, irradiaram para o resto do mundo e começaram a ser sentidos de forma mais intensa na Europa (STREEK, 2018). Trata-se, portanto, de um momento no qual os partidos ultranacionalistas (de 
extrema direita) aproveitaram para levantar antigas agendas cujas pautas ressuscitam a xenofobia, com perseguição não apenas aos imigrantes do Leste Europeu (ciganos, judeus, muçulmanos), mas também africanos, latino-americanos; a defesa de retorno às raízes da cultura local; misoginia e homofobia acentuada etc. (MUSTO, 2015).

Não devemos cair no reducionismo analítico economicista, mas tampouco desconsiderar o atual contexto de mundialização do capital especulativo-financeiro-virtual. De forma contrária ao que aconteceu no pós-guerra, quando os Estados Unidos e a Europa adotaram um modelo intervencionista (keynesiano), no qual o Estado foi capaz de garantir algum bem-estar social a uma considerável parcela da classe trabalhadora, o capital e seu braço direito (o Estado) demonstram que atualmente entrou em cena a política que fortalece seu papel, como mantenedor e reprodutor dos interesses privados daquele. Assim, ao invés de promover segurança e estabilidade de emprego, recomposição salarial, consumo em massa, previdência social, o Estado ultraneoliberal não apenas abstrai essas conquistas do conjunto das políticas públicas sociais, como enfraquece a resistência da classe trabalhadora organizada no momento em que ataca e destrói suas instituições representativas, em especial os sindicatos. Com isso, o capital e o Estado capitalista plenificam-se. Não por acaso, em Civilização e barbárie (SOUTO; NORONHA et. al., 2018), os autores denunciam a assustadora e perversa contabilidade relativa à acumulação da riqueza produzida no mundo: apenas oito dos bilionários possuem a riqueza que equivale a 3,6 bilhões de pessoas; o $1 \%$ mais rico representa a riqueza de 99\%; até 2039, quinhentas pessoas passarão mais de US\$2,1 trilhões para seus herdeiros, o que vai representar o PIB da Índia. A renda 
dos 10\% mais pobres aumentou cerca de US\$ 65 entre 1988 e 2011 enquanto a do $1 \%$ mais rico cresceu cerca de US\$11.800, 182 vezes mais.

A sofisticada racionalidade criativa da teoria ultraneoliberal considera importante que todos se tornem uma empresa (pessoa jurídica) com ganas à competição. Um olhar superficial tende a pensar que o mercado (esse ente com ares de divindade) atua livre, leve e solto das forças políticas do Estado, quando, na realidade, ambos (mercado e Estado) se retroalimentam. E, mediado por uma política neoliberal, o Estado tende a incorporar e ao mesmo tempo formatar a racionalidade do capital (DARDOT; LAVAL, 2016), de tal forma que é evidente a incompatibilidade entre neoliberalismo e Estado democrático - regime que intervém em nome dos cidadãos e, por meio do poder público, aplica a justa distribuição dos bens econômicos, como resultado do funcionamento do mercado. Assim, ao fortalecer a justiça do mercado (livre e ao mesmo tempo dependente da intervenção do Estado), em detrimento da justiça social-democracia (STREECK, 2018) -, tem-se a ilusão de que o inimigo a ser combatido é o não idêntico: os imigrantes, cujo imaginário de perigosos tem sido forjado de longa data - basta conferir os operadores da sofisticada propaganda nazifascista -, no contexto atual, renovada e mundialmente conhecida como fake news. No corpus identitário dessa ideia, prevalecem os valores da comunidade local ultranacionalista, extremista religiosa, ultraconservadora, reativa aos ideais democráticos igualdade/justiça social, liberdade - de todos e para todos que destoam da feição homogeneizante do Estado; e fraternidade - em detrimento da perspectiva cosmopolita/universal, que induz historicamente reprimidos, perseguidos e excluídos da convivência fraterna com a totalidade social. 


\section{A dimensão subjetiva: memória histórica e elaboração do} passado

Em 1948, os Estados Unidos transferiram o controle do PDA aos próprios alemães, o que contribuiu ainda mais para o seu fiascolfracasso. Como lembra Ribeiro (1979, p. 6), após a primeira fase de "desnazificação", abandonou-se qualquer investigação efetiva quanto a um eventual passado nazista dos candidatos à função pública, por exemplo. Em contrapartida, a mínima suspeita de simpatias comunistas significava a perda iminente do emprego ou mesmo o impedimento do candidato, ainda que fosse qualificado e demonstrasse todas as condições técnicas para assumir um cargo público. Na Alemanha do pós-guerra, a tentativa de destruição do passado foi uma tendência social. Como consequência, na observação de Adorno (1995a), isso implicou o desaparecimento da consciência da continuidade histórica. Constatações empíricas confirmavam a perda da memória coletiva das gerações mais jovens. Questão agravada quando, no pós-guerra, os EUA vencedores impuseram a ojeriza à história, típica da consciência pragmática estadunidense. Revelador dessa tendência seria uma citação de Henry Ford, no livro $A$ história é uma charlatanice, que segundo Adorno (1995a, p. 32) representaria "[...] a imagem terrível de uma humanidade sem memória".

$\mathrm{Na}$ acepção adorniana, sem memória, nenhum conhecimento que valha a pena pode ser alcançado. Contudo, para Adorno, a memória não é uma síntese transcendental, fora do tempo. Ela possui uma essência 
temporal que deve ser encontrada no grito das vítimas das catástrofes, cujo evento mais emblemático, na era contemporânea, foi Auschwitz: o campo de extermínio que sintetiza a intrincada engenharia de produção do genocídio. Não por acaso, Adorno (1995b) defende a tese segundo a qual, a primeira exigência para a educação é que Auschwitz não se repita. Nesse sentido, a elaboração do passado pode ser concebida como um trabalho de luto capaz de engendrar uma reconciliação com os restos da história muitas vezes congelados no limbo do inconsciente. Ela seria uma espécie de negação determinada do objeto de amor - o Führer e a ideologia nazista, que causaram o sofrimento e a morte de milhares de pessoas. Com efeito, uma terceira hipótese desse artigo considera que esse processo (elaboração do passado/trabalho de luto) não ocorreu, nem na Alemanha, sequer em outros contextos nos quais a extrema direita ou forças políticas simpáticas ao nazifascismo tomaram o poder. Não obstante, no caso específico da Alemanha, há indícios suficientes para se considerar que desde 1990, após a reunificação, até o atual momento, final da primeira década do século XXI, aquele país parece em nada lembrar o contexto no qual parte considerável da sociedade colaborou com a política nazifascista de extermínio em massa de judeus, ciganos, deficientes físicos, dissidentes políticos, militantes de esquerda dos partidos comunistas, anarquistas, sindicalistas, prostitutas e homossexuais.

Contudo, apesar da tese de Becker (2016), segundo a qual o PDA reformou o sistema educacional, alterou os currículos, introduziu novos livros didáticos, inovadores métodos pedagógicos, técnicas escolares modernizadas e, com isso, teria desnazificado as escolas alemãs, como explicar o aumento do número de simpatizantes e militantes de grupos e 
movimentos neonazistas, na Alemanha (e na quase totalidade do continente europeu), tendo como horizonte a dimensão subjetiva, que em última instância é determinada pelas condições objetivas de produção social da existência? A seguir a reflexão de Michaela Köttig (citada por GERSCHMANN, 2013), pode-se pensar: 1) na falta de reflexão dialógica, no âmbito das famílias e instituições educacionais, que problematize a colaboração da quase totalidade da sociedade alemã com o nazismo; 2) na forma como os mais velhos - avós, tios avós ainda apegados à ideologia nacionalista/nazifascista - acabam por influenciar no processo de constituição da memória coletiva dos mais jovens; 3) no paradoxo de um contexto econômico, político e social que supostamente liquidou com a ameaça comunista advinda do "socialismo real" que se desvaneceu com o fim da URSS. Com relação a essa terceira hipótese, há que se considerar que o capitalismo saiu vencedor da "Guerra Fria" (VASCONCELOS; MANSANI, 2013) e, como assinalado, sintomaticamente o neonazifascismo tem crescido não apenas na Alemanha, mas em diversos países europeus e não europeus. Trata-se, portanto, de um contexto econômico, político-social acolhedor dos ideais nacionalistas, ao mesmo tempo em que é refratário ao debate público relativo aos horrores do nazismo.

A quarta hipótese considera que, quando a discussão gira em torno dessa temática (nazismo, neonazifascismo), parece haver uma tendência em moralizar ou psicologizar o comportamento dos simpatizantes e militantes dos grupos nacionalistas, considerando-os meros delinquentes, jovens com desvio de conduta. Pari passu à análise psicologizante, há uma total despolitização do fenômeno (KÖTTIG citada por GERCHMANN, 
2013). Nesse sentido, compreender o significado do fracasso do PDA na Alemanha, mediado pelo conceito de elaboração do passado (Aufarbeitung der Vergangenheit - ADORNO, 1995a), talvez ajude a esclarecer a realidade de tantos outros contextos geopolíticos semelhantes. Isso porque, para Adorno, elaborar difere de superar o passado (Vergangenheitsbewältigung). Esse termo relaciona-se mais com a ideia de supressão ligada tanto à dimensão social quanto ao nível de consciência e inconsciência das pessoas e os respectivos processos de coerção, inibição e formatação daquilo que "deve" ser lembrado e o que supostamente "precisa" ser esquecido.

Em linhas gerais, Friedländer (2017) observa que a memória histórica, relativa à barbárie nazifascista teve ao menos quatro períodos: 1945-1948 - judicialização/punição dos crimes com visibilidade nos media; 1949-1960 - Der Stille - o silêncio; 1960-1985 - despertar estudantil e 1986 - conservadora nacional - que teve início com a querela dos historiadores. Isso significa que não ocorreu, na Alemanha, a repressão in totum da memória histórica relativa aos horrores do nazismo. Lá privilegiou-se muito mais a negação abstrata do conteúdo do trauma, que tende a suprimir a verdade e eventualmente não apenas reproduz como engendra novos sintomas. Na contramão desse procedimento, elaborar o passado exige uma negação determinada do objeto: descongelar/desformatar a memória e trazer à tona os elementos sociais disparadores e produtores da catástrofe que dizimou milhares de seres humanos; propor uma discussão honesta sobre como e por que tudo aconteceu. E isso, tanto na esfera pública, por meio de políticas públicas (educação e cultura) sociais, como no âmbito da vida privada. Negação 
determinada refere-se também ao rompimento com a semiformação, que pode ser compreendida como danificação da formação, que em geral é promovida pela ação da indústria cultural que dificulta a autonomia do indivíduo cuja relação com o tempo e a memória é formatada para potencializar a reprodução de processos formativos heterônomos (ZUIN, 2011).

\section{Palavras finais}

Este artigo problematizou questões relativas ao recrudescimento do neonazifascismo na sociedade contemporânea e o fez a partir do conceito de elaboração do passado, entendido como negação determinada do objeto. Para tanto, respondeu à algumas perguntas específicas, dentre elas: como, quando, por que, quanto tempo durou e as principais características do Programa de Desnazificação (PDA) na Alemanha do pós-guerra. Foi uma política pública bem-sucedida? Como se deu a participação da educação formal, nesse PDA? Ao longo do ensaio foi possível perceber que a política fascista/neonazifascita explicita-se a partir dos seguintes slogans e estratégias: veneração a um passado mítico e valorização de heróis míticos - geralmente homens pertencentes ou representantes de grupos política e economicamente dominantes; propaganda baseada em notícias falsas; anti-intelectualismo; defesa de uma realidade social baseada na hierarquia verticalizada; lei e ordem militarizadas; combate e ao mesmo tempo atração por tudo que diz respeito à sexualidade (ansiedade sexual); sentimento apelativo a tudo que 
se refere à pátria; desarticulação da união e o do bem-estar público; desumanização de grupos específicos da sociedade, em especial os segmentos mais pauperizados da classe trabalhadora, que fica mais vulnerável à volúpia da exploração capitalista, que pode chegar até mesmo ao extermínio generalizado. Assim, o sintoma mais marcante da política fascista é a exacerbação da divisão social. Ela divide a população em nós e eles, com forte apelo às distinções étnicas, religiosas, de gênero etc., com o intuito de moldar a ideologia e a própria política. Os políticos fascitas reescrevem a compreensão que a sociedade tem sobre a realidade. Distorcem e rebaixam a linguagem por meio da propaganda, que atualmente acontece por meio das fakenews; do anti-intelectualismo, com ataque às universidades e sistemas educacionais que possam contestar suas ideias; anti-comunismo. Contudo, sua ideologia sustenta-se na naturalização das desigualdades sociais e da não identidade dos grupos por meio de um suposto respaldo científico. A tendência é criar um estado de irrealidade, com teorias da conspiração e propagação ininterrupta de notícias falsas. Ao solidificarem as classificações e divisões sociais, a compreensão das pessoas é substituída pelo medo (STANLEY, 2019).

O recrudescimento do neonazifascismo tem a ver com o fenômeno do esquecimento e/ou formatação da memória histórica, articulado à sociedade administrada: capitalista. Todavia, o desejo de se libertar do passado é ambíguo. Na avaliação de Adorno (2010), não é possível viver à sua sombra, pois o terror não termina quando culpa e violência são pagas com a mesma moeda. Escapar do passado seria uma atitude injustificável, porque este ainda permanece vivo. O nazismo sobrevive, mas ainda não sabemos “[...] se o $f a z$ apenas como fantasma daquilo que foi monstruoso a 
ponto de não sucumbir à própria morte, ou se a disposição pelo indizível permanece presente nos homens, bem como nas condições que os cercam" (ADORNO, 2010, p. 213-214). Por sua vez, toda essa discussão, relativa ao domínio da memória histórica, tem a ver com a formação para a autonomia, com a educação formal, da qual Adorno tinha ciência dos limites. Não obstante, ele sabia que era melhor ter acesso a algum, do que nenhum esclarecimento. Por isso, considerava que a chave para a transformação decisiva residia na sociedade e em sua relação com a escola: sem nunca deixar de concebê-la como parte do sistema econômico que, em última instância, determina as mais íntimas relações intra e extraescolares. Tanto a sobrevivência do fascismo quanto o insucesso da elaboração do passado têm a ver com a persistência das condições objetivas que forjam a sua continuidade existencial (ADORNO, 1995a). Como visto, a prova disso, atualmente, revela-se na sanha da agenda política ultraneoliberal que fortalece a justiça de mercado e solapa a democracia fundada na justiça social (STREECK, 2018; DARDOT; LAVAL, 2016). Nessa direção, com Adorno (1995a) defende-se: há que se considerar tanto a ordem quanto a organização econômica que continuam a obrigar a maioria das pessoas a depender de situações dadas, em relação às quais são impotentes, além de terem que se manter em uma espécie de não emancipação. Elas querem viver, mas nada lhes resta senão adaptarem-se ao existente e renunciarem à possibilidade de autonomia que remete à ideia de democracia social. Para sobreviverem, precisam abdicar do próprio eu (ADORNO, 1995a). Por isso, desvendar os enigmas que criam um deslumbramento entorpecedor demanda um esforço rumo ao conhecimento capaz de combater o condicionamento social administrado por um Estado capitalista, cuja mão 
direita (BOURDIEU, 1998) amplia-se com a cooperação de uma esfera pública excitada por seus operadores e gerentes, ao mesmo tempo que é anestesiada pela ação da indústria cultural que livremente formata juízos de gosto, a fantasia e a memória histórica das pessoas.

Adorno (1995a) também argumentou que a educação, por si só, seria insuficiente para frear o princípio de morte que caminha de mãos dadas com o processo civilizatório. Para ele, a barbárie diz respeito a todo tipo de extremismo: a fome, o preconceito delirante, a opressão, o genocídio, a tortura e a ignorância - que, em última instância, tem a ver com a insistente e ininterrupta produção social do sofrimento coletivo humano e da natureza, em geral. Nesse contexto, o ponto de partida é a contraposição à vida danificada e, apesar de argumentos contrários, mesmo no âmbito das teorias sociais, Adorno (1995c) defende a importância da educação formal; além de sugerir que os operadores da escola também elaborem seu próprio passado; conscientizem-se do pesado legado de representações de tendência autoritária e que subjaz na história do magistério (ADORNO, 1995c, p. 117). No caso específico da memória histórica, relativa ao $3^{\circ}$ Reich, em particular sobre o genocídio de seis milhões de judeus, pesquisas indicam que no início da década de 1960, $88 \%$ dos alemães ocidentais não se sentiam responsáveis pelo extermínio em massa e, para mais da metade da população, o regime nazista não fora culpado pelos crimes de genocídio. Tal comportamento é revelador da arrogância inflada em decorrência da restauração econômica, da nova política de legitimação baseada no anticomunismo e a fria anistia que abertamente franqueou a anestesia e formatação da memória: elementos que contribuíram para dividir o sentimento de inocência coletiva 
(TRAVERSO, 1995). O problema persistiu: só a partir de 1991 o sistema educacional alemão iniciou um processo de enfrentamento do passado nazista, quando as autoridades dos vários estados federais assumiram a responsabilidade pela educação. Ainda que não houvesse um currículo único padronizado para o ensino da história moderna da Alemanha, em 1991, a agência Federal de monitoramento educacional ordenou que nas escolas os nazistas estivessem sujeitos a um "tratamento intensivo e completo" e que "a memória do Holocausto deveria ser mantida viva" (COWELL, 1995). Isso parece não ter sido suficiente. Cziesche et. al. (2005) asseguram que a falta de conhecimento de muitos alunos sobre o nazismo pode ser devastadora, pois a ideologia neonazista tornou-se uma peça importante de parte da cultura jovem alemã, que tem se tornado cada vez mais desinibida para disseminar clichês antissemitas. É o que também se observa na matéria "Na Alemanha, pais educam crianças com ideais neonazistas" (SPIEGEL ONLINE, 2011), na qual se lê que crianças de famílias neonazistas tendem a ver como fracassados tanto a democracia como o Estado alemão e o mundo ideal é a Volksgemeinschaft (comunidade do povo) idealizada pelo $3^{\circ}$ Reich. Há, inclusive, uma pedagogia neonazista que faz referência à ideologia racial, paganismo, arte nazista, antissemitismo, militância e crença na própria superioridade. A divulgação desses ideais pode ser encontrada na internet, com a reedição de livros da era nazista.

A análise mais detida sobre o contexto contemporâneo sugere defender, de forma inequívoca, a atualidade da advertência de Adorno (1995), sobre a relevância da elaboração do passado: o trabalho honesto e cristalino de negação determinada, capaz de escovar a história a 
contrapelo. A necessidade de que isso ocorra diz respeito à quase totalidade dos países, pois nosso Zeitgeist expressa que ainda não foi ultrapassada a urgência da filosofia social crítica, contrária à sociedade administrada pelo capital.

Referências

ADORNO, T. W. The meaning of working through the past. In: OLICK, J. K.; PERRIN, A. J. (Edited). Guilt and defense: On the Legacies of National Socialism in Postwar Germany. Translated by Henry W. Pickford. Harvard: Harvard University Press, 2010, p. 213-228.

ADORNO, T. W. Educação e emancipação. Tradução de Wolfgang Leo Maar. Rio de Janeiro: Paz e Terra, 1995.

ADORNO, T. W. O que significa elaborar o passado. In: Educação e emancipação. Tradução de Wolfgang Leo Maar. Rio de Janeiro: Paz e Terra, 1995a.

ADORNO, T. W. Educação após Auschwitz. In: Educação e emancipação. Tradução de Wolfgang Leo Maar. Rio de Janeiro: Paz e Terra, 1995b.

ADORNO, T. W. Tabus acerca do magistério. In: Educação e emancipação. Tradução de Wolfgang Leo Maar. Rio de Janeiro: Paz e Terra, 1995c.

BANDEIRA, L.A.M. A desordem mundial: o espectro da total dominação. $5^{\mathrm{a}}$ ed. Rio de Janeiro: Civilização Brasileira, 2018.

BARK, Dennis L; GRESS, David R. A history of West Germany (1) From shadow to substance 1945-1963. Oxford (England)/Cambridge (Massachusetts): Blackwell, 1989.

BECKERT, H. The effects of denazification on education in West Germany. Kentucky: Murray State University, Doctoral Thesis, Scholars 
Weed

4 , 2016. http://digitalcommons.murraystate.edu/cgi/viewcontent.cgi?article $=1015 \&$ context=scholarsweek. Acesso em 03. 05.2017.

BENJAMIN, W. 2012. Magia e técnica, arte e política: ensaios sobre literatura e história da cultura. Tradução de Sérgio Paulo Rouanet; prefácio Jeanne Marie Gagnebin. 8. ed. São Paulo, Brasiliense (Obras Escolhidas, v.1).

BITTAR, R. Estudo mostra relação entre gastos na campanha e eleição. Câmara dos Deputados, Câmara Notícias, 10 de maio de 2011. Disponível em:

http://www2.camara.leg.br/camaranoticias/noticias/POLITICA/196803ESTUDO-MOSTRARELACAO-ENTRE-GASTOS-NA-CAMPANHAEELEICAO.html. Acesso em 23/05/2019.

BOURDIEU, P. A mão esquerda e a mão direita do Estado. In:

Contrafogos - Táticas para enfrentar a invasão neoliberal. Rio de Janeiro: Jorge Zahar Editor, 1998, p. 9-20.

CHOMSKY, N. Socialism for the rich, capitalism for the poor: an interview with Noam Chomsky. Truthout, 11.12.2016. Disponível em: https://truthout.org/articles/socialism-for-the-rich-capitalism-for-the-pooran-interview-with-noam-chomsky/. Acesso em 04.05.2017.

COATES, M. Denazifying Germany: German protestantism and the response on denazification in the America Zone, 1945-1948. York (UK): Dissertation. Department of History, University of York, 2014. http://etheses.whiterose.ac.uk/7843/1/dissertationfinal3.pdf. Acesso em 06.07.2015.

COWELL, A. Teaching Nazi Past to German Youth. The New York Times. June. $9,1995 . \quad$ Disponível em: https://www.nytimes.com/1995/06/09/world/teaching-nazi-past-togerman-youth.html. Acesso em 10.07.2013.

CULBERT, D. American film policy in the re-education of Germany after 1945. In: The political re-education of Germany \& her allies after World 
War II, edited by Pronay, Nicholas and Wilson, Keith, Worcester: Billing\& Sons, 1985, p. 173-202. https://doi.org/10.4324/9780429284434$\underline{9}$

CZIESCHE, D.; NEUMANN, Conny; SCHMID, Barbara; SCHMIDT, Caroline; VERBEET, M; WIN, S. Para chocar pais, estudantes aderem ao nazismo. Der Spiegel., 02.06.2005. Disponível em: https://noticias.uol.com.br/midiaglobal/derspiegel/2005/06/02/para-chocarpais-estudantes-aderem-ao-nazismo.jhtm. Acessado em: 02.06.2005.

DACK, W. M. Questioning the past: the fragebogen and everyday denazification in occupied Germany. Alberta: Doctoral Thesis, Graduate Program in History, University of Calgary, 2016. https://prism.ucalgary.ca/handle/11023/2821?show=full. Acesso em 20.03.2017.

DARDOT; P.; LAVAL, C. A nova razão do mundo - ensaio sobre a sociedade neoliberal. Traduação de Mariana Echalat. São Paulo: Boitempo, 2016.

DAVIES, P. J.; Jackson, P. The far right in Europe: an encyclopedia. Greenwood, Oxford, 2008. Disponível em: http://eprints.hud.ac.uk/id/eprint/5536/2/Introduction _Defining_the_Far_Right.pdf. Acesso em 07.03.2013.

EVANS, R. J. Hitler's shadow: West German Historians and The Attempt to Escape from the Nazi Past. London: I.B. Tauris, 1989.

EVANS, R. J. Terceiro Reich na história e na memória: novas perspectivas sobre o nazismo, seu poder político, sua intrincada economia e seus efeitos na Alemanha do pós-guerra. Tradução de Renato Marques. São Paulo: Planeta do Brasil, 2018.

FOSTER, P. The rise of the far-Right in Europe is not a false alarm. The Telegraph News, 19.05.2016. Disponível em: https://www.telegraph.co.uk/news/2016/05/19/the-rise-of-the-far-right-ineurope-is-not-a-false-alarm/. Acesso em 23.10.2016. 
FREI, Nobert. Adenauer's Germany and the nazi past: the politics of amnesty and integration. Translated by Joel Golb. New York: Columbia University Press, 2002. https://doi.org/10.7312/frei11882

GERCHMANN, L. As meninas do Reich: neonazismo alemão apresenta sua nova face. Jornal Zero Hora, Porto Alegre (RS), 11.05.2013. Disponível em: https://gauchazh.clicrbs.com.br/mundo/noticia/2013/05/neonazismoalemao-apresenta-sua-nova-face-4135046.html. Acesso em 20.06.2013.

GRIFFITH, W. E. Denazification in the US Zone of Germany. The Annals of the American Academy of Political and Social Science 267, 1950, p. 6876. Disponível em: https:www.//pt.scribd.com/document/94186429/Griffith-Denazification1950. Acesso em 20.06.2013. https://doi.org/10.1177/000271625026700108

HAYEK, F. A. The economic condition of interstate federalismo. In: (org.). Individualism and economic order. Chicago: University of Chicago Press, 1958 (1939). Disponível em: http://www.library.fa.ru/files/HayekIndividualism.pdf. Acesso em: 25.05.2015.

HANNOUN, H. Nazismo - educação? domesticação?: fundamentos ideológicos da formação nazi. Lisboa: Horizontes Pedagógicos (Instituto Piaget), 1997.

HARVEY, D. 17 contradições e o fim do capitalismo. Tradução de Rogério Bettoni. São Paulo: Boitempo, 2016.

HARVEY, D.; TELES, E.; SADER, E.; et al. Ocuppy: movimentos de protesto que tomaram as ruas. São Paulo: Boitempo Editorial, 2012.

HEILIG, G.; B. T.; Lutz, W. Germany's population: turbulent past, uncertain future. Luxemburg (Austria): International Institute for Applied Systems Analysis (IIASA), Research Report (Reprint), RR-91-010. Reprinted from Population Bulletin, 45(4), p. 1-46, 1990. http://pure.iiasa.ac.at/id/eprint/3363/1/RR-91-10.pdf. Acesso em 10.06.2013. 
HERTZ, John, H. The fiasco of denazification in Germany. In: Political Science Quartely, 63, 1948, p.569-594. https://doi.org/10.2307/2144399

HOBSBAWM, E. Age of extremes: The Short Twentieth Century - 19141991. London: Abacus, 1995.

IGNATZI, C. Neo-Nazis form expanding networks beyond national borders. Deutsche Welle, 21.09.2013. Disponível em: https://www.dw.de/neo-nazis-form-expanding-networks-beyond-nationalborders/a-17104509. Acesso em 10.11.2013.

INGLEHART, R. F; NORRIS, P. Trump, Brexit, and the rise of populism: Economic Have-Nots and Cultural Backlash. Harvard Kennedy School. Faculty Research Working. Disponível em: https://papers.ssrn.com/sol3/papers.cfm?abstract_id=2818659. Acesso em 05.05.2017. https://doi.org/10.2139/ssrn.2818659

IVARSFLATEN, E.; GUDBRANDSEN, F. The populist radical right in Western Europe. Europa regional surveys of the world: western Europe, v. 2012, p. 1-5, 2012. Disponível em: https://scholar.uib.no/sites/default/files/ivarsflaten/files/manuscript_the_po pulist radical right in western europe ivarsflaten.pdf. Acesso em 05.05.2017.

LEITENBERG, M. Deaths in wars and conflicts in the 20th century. 3rd ed. New York (US): Cornwell University, Peace Studies Program, Occasional paper \#29, 2006. Disponível em: https://www.clingendael.org/sites/default/files/pdfs/20060800 cdsp occ 1 eitenberg.pdf. Acesso em 05.07.2013.

LÖWY, M. Conservadorismo e extrema direita na Europa e no Brasil. In: Revista Serviço Social e Sociedade. São Paulo, n. 124, p. 652-664, out./dez.2015. Disponível em: http://www.scielo.br/pdf/sssoc/n124/01016628-sssoc-124-0652.pdf\#page $=1 \&$ zoom $=$ auto,4,683. Acesso em 05.07.2017. https://doi.org/10.1590/0101-6628.044

MELZER, R.; SERAFIN, S. Right-wing extremism in Europe: contry analyses, counter-strategies and labor-market oriented exit strategies. 
Berlin: Friedrich Ebert Foundation, 2013. Disponível em: http://library.fes.de/pdf-files/dialog/10031.pdf. Acesso em 20.02.2014.

MESETH, W. Education after Auschwitz in a United Germany: A Comparative Analysis of the Teaching of the History of National Socialism in East and West Germany. Europeaneducation, vol. 44, $\mathrm{n}^{\mathrm{o}}$ 3, Fall, 2012, p. 13-38. https://doi.org/10.2753/EUE1056-4934440301

MUSTO, M. O avanço da extrema direita na Europa. In: Jornal da Unicamp. Campinas, 14 a 31 de dez. de 2015, p. 11. Disponível em: http://www.unicamp.br/unicamp/sites/default/files/jornal/paginas/ju 646 paginacor 1. Acesso em 05.07.2017.

PRONAY, N. To stamp out the whole tradition. In: The politicalreeducation of Germany and her allies after World War II. Edited by Pronay, Nicholas; Wilson, Keith; Kent: Croom Helm, 1985, p. 1-36. https://doi.org/10.4324/9780429284434-1

RIBEIRO, A. S. O Estado de Direito e a Repressão: o "Berufsverbot" na Alemanha Federal. Revista Crítica de Ciências Sociais, n. 3, p. 1-27, dez. 1979. Disponível em: <http://www.ces.fe.uc.pt/publicacoes/rccs/003/003.php>. Acesso em: 27 jan. 2006.

RÖHRS, H. A ciência da educação e o sistema educacional na República Federal Alemã. In: DEBESSE, Maurice; MIALARET, Gaston (Org.). Tratado das ciências pedagógicas: pedagogia comparada. Tradução de Luiz Damasco Penna e J. B. Damasco Penna. São Paulo: Nacional/USP, 1977.

STANLEY, J. Como funciona o fascismo: a política do "nós" e "eles". 2. ed. Tradução de Bruno Alexander. Porto Alegre; L\&PM, 2019.

STREECK, W. Tempo comprado: a crise adiada do capitalismo democrático. Tradução de M. Toldy e T. Toldy. São Paulo: Boitempo, 2018.

SPIEGEL ONLINE. Growing-up neo-nazi family life among germany's far-right extremists. Der Spiegel, 21.07.2011. Disponível em: 
http://www.spiegel.de/international/germany/growing-up-neo-nazi-familylife-among-germany-s-far-right-extremists-a-775764.html. Acesso em 10.06.2012.

TAYLOR, F. Exorcising Hitler: The occupation and denazification of Germany. Bloomsbury Publishing, 2011.

TØLLEFSEN, T. O. The american occupation of Germany: a representative case of nation-building? Oslo: Thesis. Department of Archaeology, Conservation and Historical Studies - University of Oslo, 2006. Disponível em: https://www.duo.uio.no/bitstream/handle/10852/23589/usingermany.pdf. Acesso em 08.06.2013.

TORRES, N. G. Neo-Nazi ideologies on the rise in Germany despite Merkel's win. Miami Herald, 25.09.2017. Disponível em: http://www.miamiherald.com/news/nationworld/world/article175338551.html. Acesso em 11.10.2017.

TRAVERSO, E. The Jews \& Germany: from the Judeo-German symbiosis to the memory of Auschwitz. Lincoln: University of Nebraska Press, 1995.

VASCONCELOS, C. M. E. et. al. As conferências internacionais de Yalta e Potsdam e sua contribuição à construção da hegemonia econômica internacional norte-americana no capitalismo pós $2^{\mathrm{a}}$ Guerra Mundial. Revista Relações Internacionais no mundo Atual, Curitiba, Unicuritiba, v. 2, no 18, 2013, p. 41-55.

Data de registro: 03/06/2019

Data de aceite: $23 / 04 / 2020$ 